\title{
Neonatal Leptin Administration Alters Regional Brain Volumes and Blocks Neonatal Growth Restriction-Induced Behavioral and Cardiovascular Dysfunction in Male Mice
}

\author{
GWEN E. ERKONEN, GREGORY M. HERMANN, RACHEL L. MILLER, DANIEL L. THEDENS, PEG C. NOPOULOS, \\ JOHN A. WEMMIE, AND ROBERT D. ROGHAIR
}

\author{
Departments of Pediatrics [G.E.E., G.M.H., R.L.M., R.D.R.], Radiology [D.L.T.], and Psychiatry [P.C.N., J.A.W.], Carver College of \\ Medicine, University of Iowa, Iowa City, Iowa 52242; Veterans Affairs Medical Center [J.A.W.], Iowa City, Iowa 52246
}

\begin{abstract}
Premature delivery is often complicated by neonatal growth restriction (GR) and neurodevelopmental impairment. Because global overnutrition increases the risk of adult metabolic syndrome, we sought a targeted intervention. Premature delivery and perinatal GR decrease circulating levels of the neurotrophic hormone leptin. We hypothesized that leptin supplementation would normalize the outcomes of mice with incipient neonatal GR. Pups were fostered into litters of 6 or 12 to elicit divergent growth patterns. Pups in each litter received injections of saline or leptin from d 4 to 14 . At 4 mo, mice underwent tail cuff blood pressure measurement, behavioral testing, and MRI. Mice fostered in litters of 12 had decreased weanling weights and leptin levels. Neonatal leptin administration normalized plasma leptin levels without influencing neonatal growth. Leptin replacement also normalized the hypertension, stress-linked immobility, conditioned fear, and amygdala enlargement seen in neonatal growth restricted male mice. In control males, neonatal leptin administration led to hypothalamic enlargement, without overt neurocardiovascular alterations. Female mice were less susceptible to the effects of neonatal GR or leptin supplementation. In conclusion, the effects of neonatal leptin administration are modulated by concurrent growth and gender. In growth restricted male mice, physiologic leptin replacement improves adult neurocardiovascular outcomes. (Pediatr Res 69: 406-412, 2011)
\end{abstract}

$\mathrm{W}$ ith advances in obstetric and neonatal care, an increasing percentage of premature infants survive to hospital discharge (1). Unfortunately, premature infants do not maintain the intrauterine growth rates of the reference fetus. Once infants reach 36 wk postmenstrual age, $89 \%$ weigh less than the 10th percentile (2). This postnatal growth restriction (GR) is associated with an increased incidence of neurodevelopmental impairment, anxiety disorders, and hypertension with male infants at disproportionate risk for such complications (1,3-5). Although nutritional interventions may improve neurodevelopmental outcomes, accelerated neonatal growth may increase the risk of type 2 diabetes mellitus and obesity (6-8). Targeted interventions to support brain growth without excessive somatic growth may thus optimize long-term neurologic, metabolic, and cardiovascular outcomes.

Received August 9, 2010; accepted November 14, 2010

Correspondence: Robert D. Roghair, M.D., University of Iowa College of Medicine, 1270 CBRB, Iowa City, IA 52242; e-mail: robert-roghair@uiowa.edu

Supported by grants from the Children's Miracle Network and the National Institutes of Health (HL102659).
Recent studies have demonstrated premature delivery and perinatal GR dramatically decrease circulating levels of the neurotrophic factor leptin (9-11). Leptin, the product of the obesity (ob) gene, is produced by adipocytes to signal satiety and suppress appetite. Leptin levels decrease dramatically during fasting or undernutrition, a response that is accentuated as adiposity declines. Beginning in the third trimester of human fetal development, transplacental leptin exposure exerts critical neurotrophic effects $(11,12)$.

Because rodents are born with neurodevelopmental immaturity, the developmental role of leptin has been modeled in neonatal mice and rats. In these studies, neonatal GR leads to circulating leptin deficiency, impaired hypothalamic development, and adult leptin resistance (13-16). Further studies have shown that mice genetically deficient for leptin (ob/ob mice) have impaired hypothalamic projections and decreased adult brain weights $(17,18)$. In leptin deficient mice, neonatal leptin replacement increases adult brain weight, myelination, and dendritic arborization $(17,18)$. We developed an isogenic GR model to test the hypothesis that neonatal leptin replacement will improve the neurodevelopmental and cardiovascular outcomes of neonatal GR mice.

\section{METHODS}

Animal model. All animal procedures were approved by the University of Iowa Animal Care and Use Committee. C57BL/6J mice were bred from initial stock (Jackson Laboratories, Bar Harbor, ME). Using an original breeding colony of 334 mice, we determined the natural distribution of birth weights and demonstrated a strong inverse relationship between litter size and pup growth (8). To isolate the effects of neonatal GR, only mice with birth weights above the 10th percentile for our colony ( $\geq 1.56 \mathrm{~g}$ ) were retained. These appropriate birth weight mice were cross-fostered into litters of 6 or 12 pups from day of life 1 to 21 to obtain control mice and neonatal GR mice, respectively. A total of 12 litters were used for these studies.

From postnatal d 4 to 14 , half of the pups within each litter were randomized to daily intraperitoneal injections of leptin $(80 \mathrm{ng} / \mathrm{g})$ whereas the other half received vehicle (10 mL/kg of normal saline) (19). On d 10, during the critical phase of leptin-dependent hypothalamic development $(14,17)$, three litters of pups were isolated from their dam for $1 \mathrm{~h}$, immediately before the scheduled saline or leptin injection. Isoflurane anesthesia was induced, plasma was collected by cardiac puncture, and leptin levels were assessed by enzyme immunoassay, as previously described (20). The remaining pups were weaned on d 20. Adult phenotypes were evaluated beginning at 4 mo.

Abbreviations: GR, growth restriction; PTSD, posttraumatic stress disorder; SBP, systolic blood pressure 


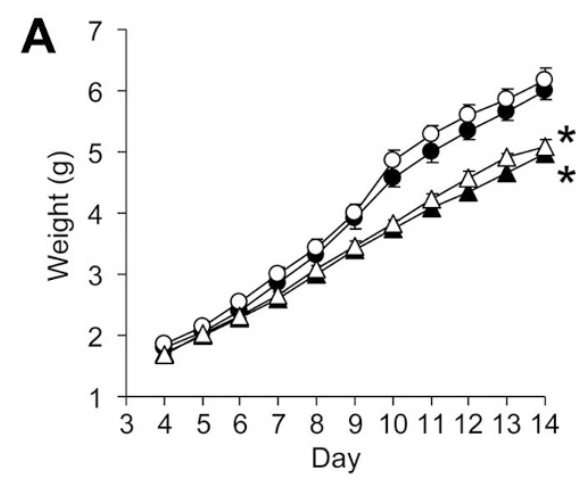

Figure 1. Male and female pups were crossfostered into litters of 6 (circles) or 12 (triangles). From d 4 to 14, half the pups in each litter received leptin $(80 \mathrm{ng} / \mathrm{g} / \mathrm{d}$, open symbols or bars), whereas littermates received an equal volume of normal saline $(10 \mathrm{~mL} / \mathrm{kg} / \mathrm{d}$, solid symbols or bars). Although mice fostered in litters of 12 had decreased neonatal weights $\left(F_{(1,740)}=\right.$ $52, * p<0.001)$, leptin administration did not acutely influence pup weight $\left(F_{(1,720)}=1.4, p=\right.$ 0.24) (A). Plasma leptin levels were influenced by an interaction between litter size and leptin $\left(B ; F_{(1,7)}=67, * p<0.001 v s\right.$ litters of 6 and $\dagger p<0.001$ vs saline).
Adult phenotypes. Tail cuff systolic blood pressure (SBP) and heart rate were measured 30 times daily for 5 consecutive days, as previously described (20). At least $1 \mathrm{wk}$ after the hemodynamic measurements, mice were placed in a $40.6 \mathrm{~cm}$ by $40.6 \mathrm{~cm}$ brightly illuminated open field. Open field testing was used to assess overall locomotor activity. Measuring the relative avoidance of the $25.4 \mathrm{~cm}$ by $25.4 \mathrm{~cm}$ central region (thigmotaxis) further screened for the presence of unconditioned anxiety.

Mice then underwent fear conditioning. On the training day, mice were placed in a fear-conditioning chamber (MED Associates, St. Albans, VT). After $3 \mathrm{~min}$, they were presented with a tone $(80 \mathrm{~dB}, 20 \mathrm{~s})$ that coterminated with an electric foot-shock $(0.5 \mathrm{~mA}, 1 \mathrm{~s})$, a total of 5 times at 2-min intervals. The time spent in a characteristic posture (freezing) was recorded by automated video tracking software whenever the only movement was respiration. The following day, cue conditioned fear was assessed by placing the mice in a novel context. The amount of time spent freezing was continuously recorded for $10 \mathrm{~min}$, including $3 \mathrm{~min}$ of baseline, $3 \mathrm{~min}$ of representation of the learned auditory cue (tone), and $4 \mathrm{~min}$ of recovery. This fear-conditioning protocol measures memory of an aversive experience (freezing during the tone) and the persistence of the fear-related response (posttone freezing).

Adult morphology. After the cardiovascular and behavioral phenotypes were assessed, MRI was completed with a 4.7-Tesla Varian Unity/INOVA system (Varian Inc., Palo Alto, CA). T1-weighted images were acquired in axial, sagittal, and coronal planes using a fast spin-echo pulse sequence with $\mathrm{TR} / \mathrm{TE}=600 / 12 \mathrm{~ms}$, and echo train length of 2 . In addition, a more T2-weighted scan with TR/TE $=1600 / 48 \mathrm{~ms}$ and echo train length of 8 was acquired. Following acquisition, MR data were transferred to the Psychiatry Iowa Neuroimaging Consortium image processing laboratory for postprocessing with the BRAINS2 software package (21). The skull stripped T2 images were registered to the MAP2006.t2avg.nii.gz image from the MBAT Atlas created by Mouse BIRN using a nonrigid affine transformation. MRI acquisition and processing were completed by investigators blinded to group assignment. At the completion of the studies, weight and length were recorded and isoflurane anesthesia was induced for organ measurement. Lengths were not obtained for the first 10 males ( 4 control-saline, 4 GR-saline, 1 controlleptin, and 1 GR-leptin).

Data analyses. All values are presented as mean \pm SE. Each group was comprised of mice from at least five separate litters. The effect of litter size or leptin administration on pup weight from d 4 to 14 was assessed by two-way repeat measures ANOVA. Absolute MRI volumes were compared by twotailed $t$ tests. All other data were compared by two-way ANOVA, factoring for neonatal GR and leptin administration. Post hoc analysis (Holm-Sidak method) was performed if statistically significant differences were detected. When ANOVA identified a significant interaction between neonatal GR and leptin, data were compared by unpaired two-tailed $t$ tests. A value of $p<0.05$ was considered significant. The ANOVA F-statistics and degrees of freedom, followed by the results of post hoc testing are given in figure legends. All analyses were performed using SigmaStat 3.0 (SPSS Inc., Chicago, IL).

\section{RESULTS}

Animal model. Mice fostered in litters of 12 pups developed neonatal GR and decreased plasma leptin levels (Fig. 1). Although leptin administration did not significantly alter neonatal growth (Fig. 1A), the daily leptin injections increased circulating leptin levels in GR mice (Fig. $1 B, p<0.001$ ). At $4 \mathrm{mo}$, we began to assess the effects of neonatal leptin supplementation on adult neurocardiovascular outcomes.

Adult phenotypes. Among male mice, tail cuff SBP was influenced by an interaction between neonatal growth and neonatal leptin administration (Fig. 2A). Post hoc testing showed neonatal GR increased the SBP of mice that had not received concurrent leptin supplementation. Although neonatal growth or leptin administration did not significantly alter female SBP $(p=$ 0.88 and $p=0.08$, respectively), neonatal leptin administration significantly decreased adult female heart rates (Fig. 2B). Because tail cuff measurements are obtained within an unfamiliar stress-evoking environment, we proceeded to investigate anxietyrelated behavioral phenotypes.

Mice were first placed within a brightly illuminated open field. Among male mice, neonatal GR led to an overall reduction in open field activity $(p<0.01)$, and post hoc testing identified a significant reduction in saline-treated but not leptin-treated mice (Fig. 3A). Although the same mice
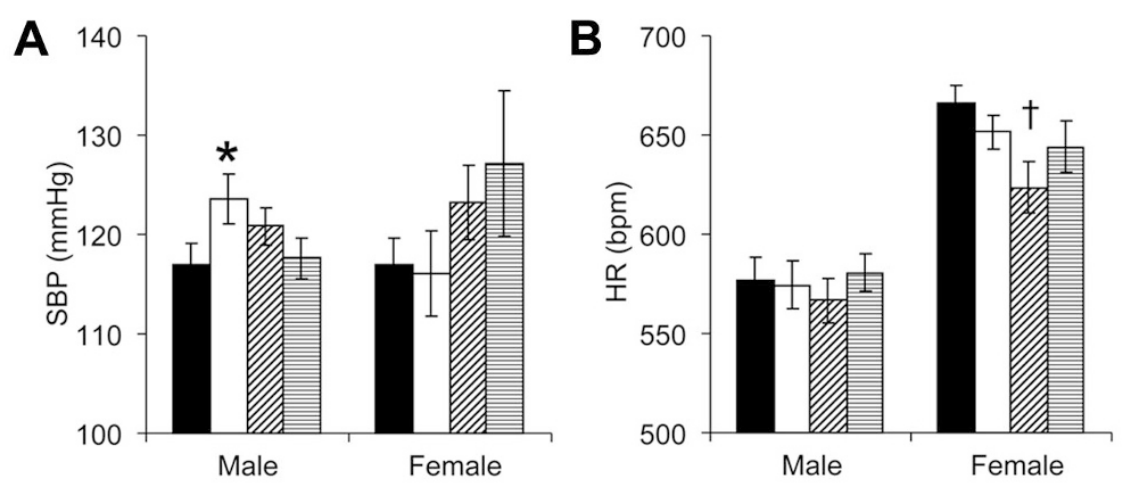

Figure 2. Tail cuff SBPs $(A)$ and heart rates $(\mathrm{HR}, B)$ were measured in adult mice that received neonatal injections of saline or leptin $(\boldsymbol{\square}$ : control-saline, $n=8$ male, 10 female; $\square$ : GRsaline, $n=15$ male, 8 female; $\mathbb{Z}$ : control-leptin, $n=14$ male, 9 female; and 目: GR-leptin, $n=$ 14 male, 6 female). Male SBP was influenced by a significant interaction between neonatal GR and leptin administration $\left(A ; F_{(1,47)}=4.2,{ }^{*} p<\right.$ 0.05 vs control-saline and GR-leptin mice). In female controls, neonatal leptin administration tended to increase adult $\operatorname{SBP}\left(A ; F_{(1,29)}=3.2\right.$, $p=0.08)$ and significantly decreased adult HR $\left(B ; F_{(1,29)}=4.4, \dagger p<0.05\right.$ vs control-saline $)$. 

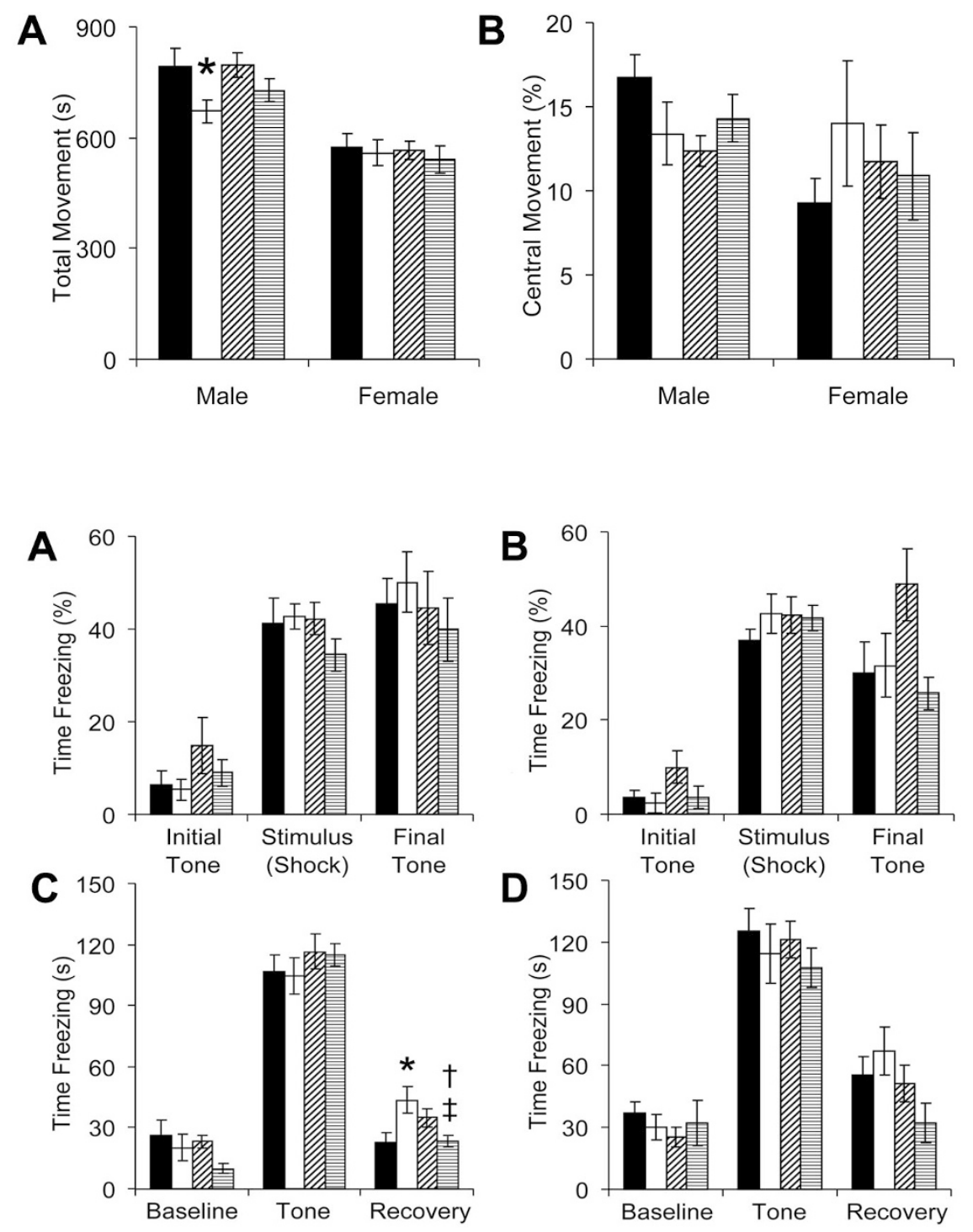

Figure 3. At least 1 wk after the tail cuff measurements, adult mice that received neonatal saline or leptin were placed within an open field (ם: control-saline, $n=8$ male, 10 female; $\square$ : GR-saline, $n=14$ male, 8 female; $\mathbb{Z}$ : controlleptin, $n=12$ male, 9 female; and 目: GR-leptin, $n=15$ male, 6 female). Video tracking software recorded movement throughout the $1648 \mathrm{~cm}^{2}$ of open space $(A)$, including movements exploring the central $645 \mathrm{~cm}^{2}(B)$. Neonatal GR decreased the activity of adult males $\left(A ; F_{(1,45)}=7.0\right.$, $* p<0.05$ vs control-saline).

Figure 4. Adult mice that received neonatal saline or leptin underwent fear conditioning ( $\mathbf{\square}$ : control-saline, $n=9$ male, 10 female; $\square$ : GRsaline, $n=15$ male, 8 female; $\mathbb{Z}$ : control-leptin, $n=14$ male, 9 female; and 冒: GR-leptin, $n=$ 15 male, 6 female). On the initial training day, male $(A)$ and female mice $(B)$ were presented with a repetitive tone that coterminated with a mild electrical stimulus, and fearful behavior (freezing) was digitally captured. The following day, male $(C)$ and female mice $(D)$ were presented with an unpaired cue (tone) in a novel context. The postcue freezing of male mice was influenced by a significant interaction between neonatal growth and leptin administration $(C$; $F_{(1,49)}=11, * p<0.05$ vs control-saline, $\dagger p<$ 0.01 vs GR-saline, $\ddagger p<0.05$ vs control-leptin). In female mice, neonatal leptin administration tended to decrease overall posttone freezing $(D$; $\left.F_{(1,29)}=3.8, p=0.06\right)$.
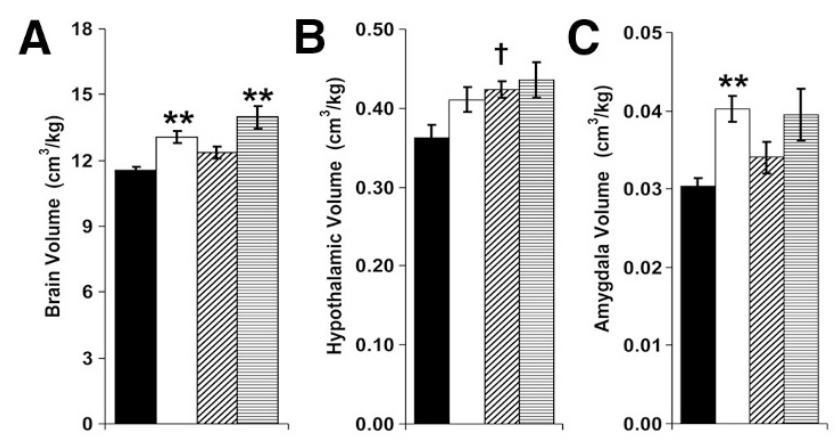

Figure 5. MRI was performed to assess male mice for neonatal GR or leptininduced alterations in regional brain volumes $(\boldsymbol{\square}$ : control-saline, $n=15 ; \square$ : GR-saline, $n=12$; $\mathbb{Z}$ : control-leptin, $n=8$; and 具: GR-leptin, $n=6$ ). Compared with control mice, GR mice had increased brain volume to body weight ratios $\left(A ; F_{(1,37)}=26, * * p<0.01 v s\right.$ corresponding control). Although neonatal leptin administration also increased relative brain volumes $\left(A ; F_{(1,37)}=\right.$ 7.3, $p=0.01)$, no significant pair-wise differences were present $(p=0.06$ for control-leptin $v s$ control-saline and $p=0.07$ for GR-leptin $v s$ GR-saline). Relative hypothalamic volumes were significantly increased by neonatal leptin supplementation $\left(B ; F_{(1,37)}=5.1, \dagger p=0.02\right.$ for control-leptin $v s$ control-saline). Neonatal GR significantly increased relative amygdala volumes $\left(C ; F_{(1,37)}=14\right.$, $* * p<0.001$ GR-saline $v s$ control-saline, $p=0.11$ GR-leptin $v s$ control-leptin).

tended to avoid movement into the center of the open field (Fig. $3 B$ ), this did not approach statistical significance $(p=$ $0.17)$. No significant alterations in open field movement were observed in female mice. Because the overall reduction in open field activity may reflect either sedentary behavior or anxiety-related immobility, we further assessed murine activity with a fear-conditioning protocol that assesses baseline activity and fear-related freezing.

During fear conditioning, neonatal GR or leptin administration did not significantly alter baseline activity, the acute response to electrical stimulation, or the conditioned response to the paired tone (Fig. 4). A significant interaction between neonatal GR and neonatal leptin administration influenced freezing time in the immediate posttone recovery phase. For male mice (Fig. 4C), neonatal GR significantly increased posttone freezing and neonatal leptin administration decreased this response. Although leptin tended to increase the posttone freezing of control mice, this did not reach statistical significance $(p=0.09)$. For female mice (Fig. $4 D)$, neonatal leptin administration tended to decrease posttone freezing behavior, but this was not statistically significant (ANOVA $p=0.06$ ). 
Although ANOVA did not identify an overall effect of GR or leptin among females, it is noteworthy that neonatal leptin decreased the freezing of GR female mice, both during training (Fig. $4 B$, final tone, $p<0.05$ versus control-leptin) and during the posttone recovery phase (Fig. $4 C, p<0.05$ versus control-leptin). Because cue-based fear conditioning involves the same brain regions (amygdala and hippocampus) implicated in human posttraumatic stress disorder (PTSD) (22), we next investigated the effects of neonatal GR and leptin administration on regional brain volumes in male mice.

Adult morphology. When normalized to body weight, relative brain volume was significantly increased by neonatal GR (brain sparing) (Fig. 5A). Neonatal leptin increased relative hypothalamic volumes, specifically for control mice (Fig. 5B). Adult male amygdala volumes were dramatically increased in GR mice that did not receive neonatal leptin supplementation, whether amygdala volumes were normalized to body weight or compared in absolute terms (Fig. 5C and Table 1, respectively). Compared with leptin-treated controls (that had relative hypothalamic enlargement), leptin-treated GR mice had increased basal ganglia volumes and decreased cerebral cortex and hypothalamic volumes (Table 1). In female mice, neonatal GR led to an absolute increase in brain stem volumes (Table 1). Because female GR-saline mice did not have significant alterations in fear conditioning or brain volumes, MRIs were not obtained on leptin-exposed females. These data are consistent with a "brain-sparing" effect of neonatal GR, a trophic effect of neonatal leptin on hypothalamic development (23), and a potential relationship between programmed susceptibility to fear and adult amygdala volumes. To better define the tissue-specific effects of neonatal GR and neonatal leptin, organ weights were obtained.

Overall, neonatal GR decreased the adult weights of male and female mice (Fig. 6A), but no significant pair-wise differences were identified on post hoc testing. For male mice, neonatal leptin supplementation increased (normalized) the length of GR mice (Fig. 6B). For female mice, neonatal GR led to increased brain weight to body weight ratios (Fig. 6C). As expected from our previous studies (20), neonatal GR decreased adult white adipose (Fig. $6 D$ ) and brown adipose (Fig. 6E).

\section{DISCUSSION}

The sequelae of prematurity include both neurocognitive impairment and a higher incidence of psychiatric illness $(1,24,25)$. Compared with females, premature males have both a survival and a developmental disadvantage. The etiologies of these sexually dimorphic outcomes are unknown but may relate to sex-specific developmental trajectories $(1,4,26,27)$. Our previous studies showed that catch-up growth normalized markers of anxiety and hypertension in males but not in females, suggesting gender-specific windows of developmental susceptibility or reversibility exist, with males have a relative delay in neuromaturation (8).

Our current studies are the first to show that neonatal leptin replacement improves the behavioral outcomes and blood pressures of neonatal GR male mice. Phenotypic and morpho- logic correction after leptin supplementation demonstrates the potential protective effects of targeted neonatal interventions. Our data further support a series of studies in which both the dosage and timing of leptin administration are key determinants of the regimen's acute and long-term effects $(19,28,29)$. The administration of exogenous leptin $(80-250 \mathrm{ng} / \mathrm{g} / \mathrm{d})$ to leptin-replete animals induces adult leptin resistance, inactivity, and obesity, whereas leptin administration to GR offspring elicits protective effects $(28-30)$. Consistent with those studies, we noted altered regional brain volumes and trends toward higher blood pressures and heightened anxiety in wellnourished mice that received neonatal leptin. Interestingly, the dose of leptin we used $(80 \mathrm{ng} / \mathrm{g} / \mathrm{d})$ did not increase the preinjection leptin levels of control mice. This may have been due to a down-regulation of endogenous leptin production.

In addition to the dose of leptin, the timing of administration influences short-term and long-term responses. Leptin administration beyond the critical window of neurodevelopmental plasticity does not elicit persistent neurotrophic effects, whereas normalization of circulating leptin levels during the establishment of the leptin-dependent anorexigenic pathway permanently influences adult brain structure and function (17). Furthermore, when the same dose of leptin $(80 \mathrm{ng} / \mathrm{g} / \mathrm{d})$ is administered to the lactating dam rather than the pup, diametrical results are noted, with decreased rather than heightened anxiety-like behavior in the exogenous leptin-exposed adult mice $(19,31)$. Further studies are necessary to clarify the optimal dose, route, and timing of leptin supplementation for at-risk populations.

We used two tests that assess both baseline activity and anxiety or fear-related behavior. Intriguingly, neonatal GR led to decreased open field activity without altering baseline testing during fear conditioning. It is important to note our open field testing protocol measured horizontal beam breaks for $30 \mathrm{~min}$, whereas fear conditioning measured all movement beyond respiration for $3 \mathrm{~min}$. Overall, mice were moving horizontally $37 \%$ of the time they were in the open field and had movements beyond respiration $87 \%$ of the time they were in the fear-conditioning chamber. We speculate the open field measurements are a better marker of general activity, whereas baseline movement during fear conditioning assesses exploratory behavior.

Our previous studies have shown neonatal catch-up growth normalizes neurobehavioral and cardiovascular phenotypes in IUGR male but not female mice (8). Those studies emphasized the importance of the perinatal environment in the resetting of adult disease susceptibility and suggested a delayed window of vulnerability among male mice $(26,32)$. This study supports and extends our earlier observations in demonstrating the protective effects of neonatal leptin and detrimental effects of neonatal GR on the cardiovascular, behavioral, and growth phenotypes of male mice. Our hemodynamic data highlight the sexually dimorphic and interdependent effects of neonatal GR and leptin administration. In leptintreated females, the finding of relative bradycardia suggests the presence of alterations in central hemodynamic regulation that require further investigation, including assessment of baroreceptor sensitivity by radiotelemetry. 
Table 1. Adult brain and brain stem volumes were measured by MRI for neonatal GR and control mice with or without neonatal leptin administration

\begin{tabular}{|c|c|c|c|c|}
\hline & \multicolumn{4}{|c|}{ Male } \\
\hline & Control & GR & Control leptin & GR leptin \\
\hline $\mathrm{N}$ & 15 & 12 & 8 & 6 \\
\hline Cerebral cortex $\mathrm{mm}^{3}$ (\% total) & $148 \pm 4(33.2 \pm 0.4)$ & $148 \pm 3(33.2 \pm 0.4)$ & $154 \pm 2(33.7 \pm 0.3)$ & $144 \pm 3^{*}\left(32.7 \pm 0.3^{*}\right)$ \\
\hline Brain stem, $\mathrm{mm}^{3}$ (\% total) & $80.8 \pm 1.5(18.1 \pm 0.2)$ & $80.7 \pm 1.0(18.1 \pm 0.1)$ & $83.0 \pm 1.1(18.2 \pm 0.1)$ & $81.0 \pm 1.4(18.4 \pm 0.1)$ \\
\hline Fiber tracts, $\mathrm{mm}^{3}$ (\% total) & $79.7 \pm 1.6(17.9 \pm 0.2)$ & $78.8 \pm 1.3(17.6 \pm 0.2)$ & $79.8 \pm 1.6(17.5 \pm 0.3)$ & $77.6 \pm 1.2(17.6 \pm 0.2)$ \\
\hline Cerebellum, $\mathrm{mm}^{3}$ (\% total) & $43.2 \pm 0.7(9.69 \pm 0.15)$ & $43.3 \pm 1.0(9.69 \pm 0.20)$ & $44.5 \pm 0.5(9.77 \pm 0.10)$ & $43.5 \pm 0.9(9.87 \pm 0.10)$ \\
\hline Hippocampus, $\mathrm{mm}^{3}$ (\% total) & $22.7 \pm 0.4(5.10 \pm 0.15)$ & $23.4 \pm 0.4(5.24 \pm 0.13)$ & $22.8 \pm 0.6(5.01 \pm 0.17)$ & $22.8 \pm 0.3(5.18 \pm 0.11)$ \\
\hline Thalamus, $\mathrm{mm}^{3}$ (\% total $)$ & $18.9 \pm 0.3(4.25 \pm 0.12)$ & $18.7 \pm 0.2(4.19 \pm 0.06)$ & $18.6 \pm 0.2(4.08 \pm 0.05)$ & $18.9 \pm 0.1(4.30 \pm 0.07)$ \\
\hline Hypothalamus, $\mathrm{mm}^{3}$ (\% total) & $11.3 \pm 0.7(2.53 \pm 0.14)$ & $11.4 \pm 0.6(2.54 \pm 0.12)$ & $12.7 \pm 0.4(2.79 \pm 0.08)$ & $11.1 \pm 0.4 *\left(2.50 \pm 0.06^{*}\right)$ \\
\hline Ventricles, $\mathrm{mm}^{3}$ (\% total) & $3.4 \pm 0.2(0.76 \pm 0.03)$ & $3.2 \pm 0.1(0.72 \pm 0.03)$ & $3.2 \pm 0.1(0.71 \pm 0.01)$ & $3.3 \pm 0.1(0.75 \pm 0.03)$ \\
\hline Pituitary, $\mathrm{mm}^{3}$ (\% total) & $2.1 \pm 0.2(0.47 \pm 0.03)$ & $2.2 \pm 0.2(0.50 \pm 0.04)$ & $2.2 \pm 0.1(0.48 \pm 0.02)$ & $2.1 \pm 0.1(0.49 \pm 0.03)$ \\
\hline Amygdala, $\mathrm{mm}^{3}$ (\% total) & $0.95 \pm 0.04(0.21 \pm 0.01)$ & $1.12 \pm 0.07 \dagger(0.25 \pm 0.02 \dagger)$ & $1.01 \pm 0.04(0.22 \pm 0.01)$ & $0.99 \pm 0.07(0.23 \pm 0.01)$ \\
\hline
\end{tabular}

MRI was not performed on leptin-exposed females.

$* p<0.05$ vs control.

$\dagger p<0.01 v s$ control.
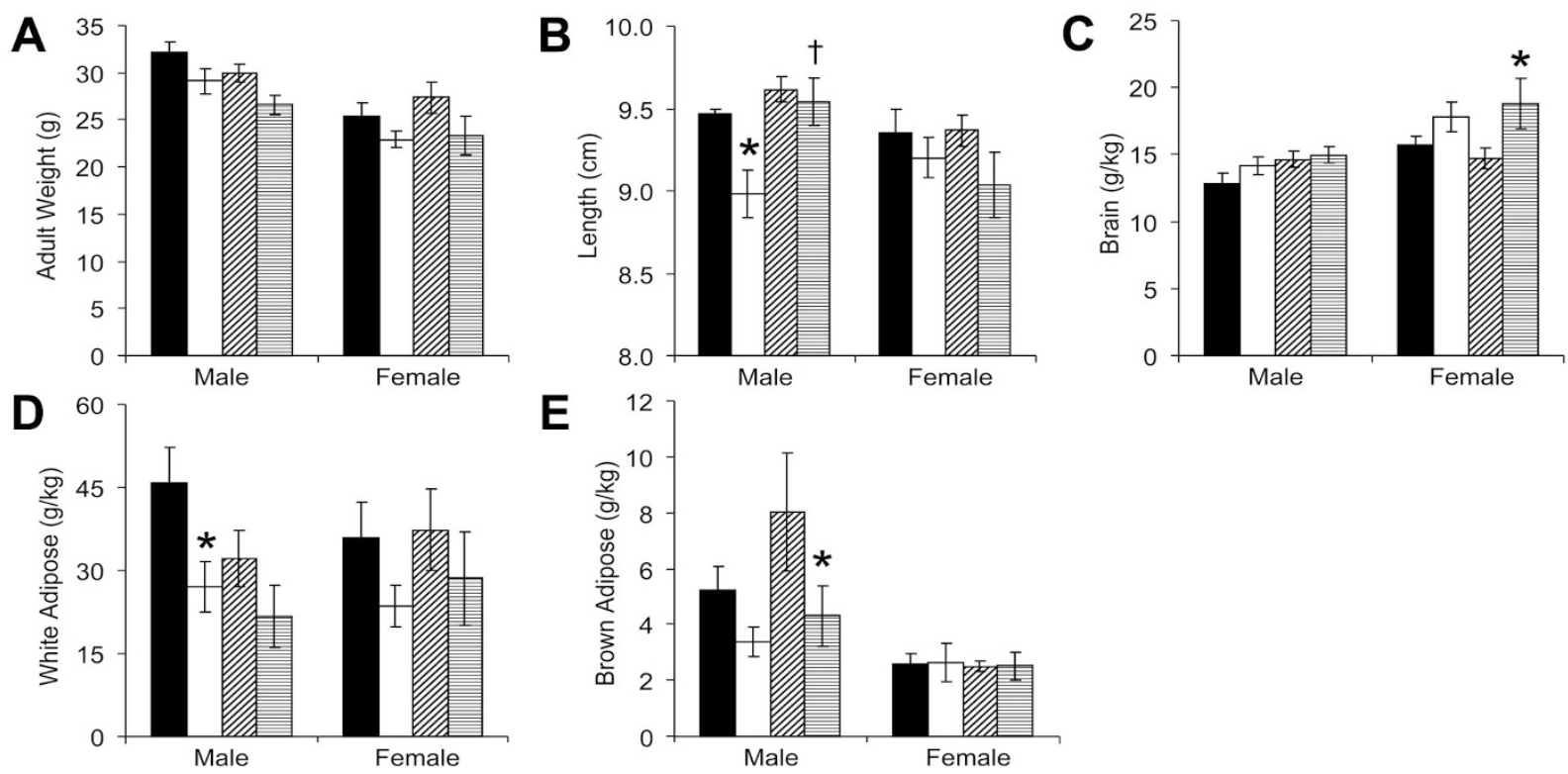

Figure 6. At study completion, male and female GR mice weighed significantly less than their control counterparts $\left(A ;\right.$ males: $F_{(1,28)}=7.7, p=0.01 ;$ females: $\left.F_{(1,27)}=4.9, p<0.05\right)$, but post hoc testing did not isolate significant differences within subgroups of saline-treated or leptin-treated mice ( $\mathbf{\square}$ : control-saline, $n=7$ male, 8 female; $\square$ : GR-saline, $n=9$ male, 8 female; $\mathbb{Z}$ : control-leptin, $n=7$ male, 9 female; and 目: GR-leptin, $n=9$ male, 6 female). Neonatal GR deceased adult male length $\left(B ; F_{(1,18)}=4.3,{ }^{*} p<0.05 v s\right.$ control-saline). Furthermore, neonatal leptin administration increased the length of adult male mice $\left(B, F_{(1,18)}=7.9, \dagger p<0.01 v s\right.$ GR-saline $)$. In female mice, neonatal GR increased relative brain weights $\left(C, F_{(1,27)}=8.1,{ }^{*} p<0.05 v s\right.$ control-leptin). In male mice, neonatal GR decreased white adipose tissue $\left(D, F_{(1,28)}=7.6,{ }^{*} p<0.05\right.$ GR-saline $v s$ control-saline and $p=0.18$ GR-leptin $v s$ control-leptin) and brown adipose tissue $\left(E, F_{(1,28)}=6.0, p=0.28\right.$ GR-saline $v s$ control-saline and $* p<0.05$ GR-leptin $v s$ control-leptin $)$.

Beyond improved cardiovascular regulation, leptin treatment rescued the behavioral alterations seen in our novel model. Neonatal GR led to a constellation of phenotypes in male mice that are reminiscent of human PTSD, including anxiety, fearfulness, and hypertension. Consistent with our MRI and fear-conditioning results, elegant studies have demonstrated a correlation between amygdala volumes and freezing to conditioned stimuli (33). Similarly, clinical studies have shown increased amygdala volumes in patients with autism, a disorder with marked male-dominated sexual dimorphism $(32,34,35)$. The etiology of this amygdala overgrowth requires further investigation, with alterations in glucocorticoid signaling among the factors thought to influence amygdala development (36).

Leptin treatment decreased posttone freezing in male and female mice, showing that a targeted intervention can reverse the programming effects of GR. The unique finding of increased posttone freezing in our baseline studies is not the expected outcome in classic fear-conditioning models (22). Fear-conditioning studies generally assess the acute response to the conditioned stimulus (freezing during the tone). We speculate the failure of the GR male mice to resolve their 
Table 1. (Continued)

\begin{tabular}{lcc}
\hline & & Female \\
\cline { 2 - 3 } & Control & 6 \\
$\mathrm{~N}$ & 7 & $457 \pm 5$ \\
Total volume $\left(\mathrm{mm}^{3}\right)$ & $449 \pm 8$ & $152 \pm 4(33.3 \pm 0.5)$ \\
Cerebral cortex, $\mathrm{mm}^{3}(\%$ total $)$ & $147 \pm 4(32.7 \pm 0.3)$ & $84.4 \pm 1.1 *(18.4 \pm 0.1 *)$ \\
Brain stem, $\mathrm{mm}^{3}(\%$ total $)$ & $80.6 \pm 1.1(17.9 \pm 0.1)$ & $83.7 \pm 1.0(18.3 \pm 0.2)$ \\
Fiber tracts, $\mathrm{mm}^{3}(\%$ total $)$ & $83.0 \pm 2.3(18.5 \pm 0.3)$ & $43.5 \pm 0.8(9.51 \pm 0.27)$ \\
Cerebellum, $\mathrm{mm}^{3}(\%$ total $)$ & $44.9 \pm 0.8(10.00 \pm 0.09)$ & $33.2 \pm 0.3(7.26 \pm 0.10)$ \\
Basal ganglia, $\mathrm{mm}^{3}(\%$ total $)$ & $33.4 \pm 0.4(7.45 \pm 0.18)$ & $21.7 \pm 0.3(4.74 \pm 0.11)$ \\
Hippocampus, $\mathrm{mm}^{3}(\%$ total $)$ & $23.0 \pm 0.6(5.13 \pm 0.19)$ & $18.9 \pm 0.2(4.14 \pm 0.06)$ \\
Thalamus, $\mathrm{mm}^{3}(\%$ total $)$ & $18.8 \pm 0.2(4.18 \pm 0.06)$ & $12.5 \pm 1.0(2.72 \pm 0.21)$ \\
Hypothalamus, $\mathrm{mm}^{3}(\%$ total $)$ & $11.4 \pm 0.8(2.53 \pm 0.14)$ & $3.4 \pm 0.1(0.75 \pm 0.03)$ \\
Ventricles, $\mathrm{mm}^{3}(\%$ total $)$ & $3.2 \pm 0.1(0.70 \pm 0.02)$ & $2.2 \pm 0.2(0.49 \pm 0.03)$ \\
Pituitary, $\mathrm{mm}^{3} \%$ total $)$ & $2.0 \pm 0.2(0.45 \pm 0.04)$ & $1.08 \pm 0.05(0.24 \pm 0.01)$ \\
Amygdala, $\mathrm{mm}^{3}(\%$ total $)$ & $0.96 \pm 0.05(0.21 \pm 0.01)$ & \\
\hline
\end{tabular}

fearful response immediately after the tone terminated may predict the risk for chronic stress-associated disorders. The mechanism for this has not been elucidated but may be due to hypothalamic pituitary adrenal (HPA) axis dysregulation. Because fear conditioning and PTSD involve acquisition and retention of fearful memories, respond to the same therapies, and depend on the same anatomic substrates (amygdala and hippocampus), fear conditioning is widely used to model PTSD (33). As in PTSD, fear conditioning in our model was also associated with adverse cardiovascular endpoints (37).

Leptin's role in fetal and infant neuronal development makes it an attractive candidate to reverse the deleterious neurocognitive and behavioral phenotypes associated with prematurity and IUGR. A recent post hoc evaluation of data from a nutritional intervention trial showed strong correlations between breast milk intake, brain volumes, and intelligence that was isolated to males (38). Breast milk contains a number of trophic factors, including leptin, which are not present in infant formulas. In our studies, neonatal leptin administration had robust effects on adult brain volumes.

Importantly, leptin supplementation offered neurodevelopmental protection without metabolic compromise as evidenced by a sustained decrease in adiposity for GR mice. The observed decrease in length of GR male mice is consistent with short stature in premature or IUGR infants. Our studies show that leptin supplementation can preemptively normalize linear growth. This effect on linear growth may reflect the hormone's effects on hypothalamic development (12). The lack of an acute effect on pup growth is consistent with studies showing that during the critical neonatal window, leptin triggers the development of leptin-sensitive circuits. It is not until d 14 that these circuits have the capacity to alter orexic behavior (17).

Our studies demonstrate that leptin supplementation can block the programming of behavioral phenotypes in mice. Exogenous leptin administration has been shown to elicit neurotrophic effects for IUGR piglets and genetically leptindeficient humans $(39,40)$. Our results translate most directly to the premature population who must undergo critical phases of neurodevelopment without the benefit of transplacental leptin. Future studies are necessary to determine whether neonatal leptin can improve the behavioral and cardiovascular outcomes of premature or IUGR infants.

\section{REFERENCES}

1. Saigal S, Doyle LW 2008 An overview of mortality and sequelae of preterm birth from infancy to adulthood. Lancet 371:261-269

2. Dusick AM, Poindexter BB, Ehrenkranz RA, Lemons JA 2003 Growth failure in the preterm infant: can we catch up? Semin Perinatol 27:302-310

3. Eriksson JG, Forsén TJ, Kajantie E, Osmond C, Barker DJ 2007 Childhood growth and hypertension in later life. Hypertension 49:1415-1421

4. Kesler SR, Reiss AL, Vohr B, Watson C, Schneider KC, Katz KH, MallerKesselman J, Silbereis J, Constable RT, Makuch RW, Ment LR 2008 Brain volume reductions within multiple cognitive systems in male preterm children at age twelve. J Pediatr 152:513-520

5. Schothorst PF, Swaab-Barneveld H, van Engeland H 2007 Psychiatric disorders and MND in non-handicapped preterm children. Prevalence and stability from school age into adolescence. Eur Child Adolesc Psychiatry 16:439-448

6. Rotteveel J, van Weissenbruch MM, Twisk JW, Delemarre-Van de Waal HA 2008 Infant and childhood growth patterns, insulin sensitivity, and blood pressure in prematurely born young adults. Pediatrics 122:313-321

7. Beardsall K, Ong KK, Murphy N, Ahmed ML, Zhao JH, Peeters MW, Dunger DB 2009 Heritability of childhood weight gain from birth and risk markers for adult metabolic disease in prepubertal twins. J Clin Endocrinol Metab 94:3708-3713

8. Hermann GM, Miller RL, Erkonen GE, Dallas LM, Hsu E, Zhu V, Roghair RD 2009 Neonatal catch up growth increases diabetes susceptibility but improves behavioral and cardiovascular outcomes of low birth weight male mice. Pediatr Res 66:53-58

9. Devaskar SU, Ollesch C, Rajakumar RA, Rajakumar PA 1997 Developmental changes in ob gene expression and circulating leptin peptide concentrations. Biochem Biophys Res Commun 238:44-47

10. Pighetti M, Tommaselli GA, D’Elia A, Di Carlo C, Mariano A, Di Carlo A, Nappi C 2003 Maternal serum and umbilical cord blood leptin concentrations with fetal growth restriction. Obstet Gynecol 102:535-543

11. Valūniene M, Verkauskiene R, Boguszewski M, Dahlgren J, Lasiene D, Lasas L, Wikland KA 2007 Leptin levels at birth and in early postnatal life in small- and appropriate-for-gestational-age infants. Medicina (Kaunas) 43:784-791

12. Kelesidis T, Kelesidis I, Chou S, Mantzoros CS 2010 Narrative review: the role of leptin in human physiology: emerging clinical applications. Ann Intern Med 152:93100

13. Remmers F, Fodor M, Delemarre-van de Waal HA 2008 Neonatal food restriction permanently alters rat body dimensions and energy intake. Physiol Behav 95:208215

14. Delahaye F, Breton C, Risold PY, Enache M, Dutriez-Casteloot I, Laborie C, Lesage J, Vieau D 2008 Maternal perinatal undernutrition drastically reduces postnatal leptin surge and affects the development of arcuate nucleus proopiomelanocortin neurons in neonatal male rat pups. Endocrinology 149:470-475

15. Passos MC, Vicente LL, Lisboa PC, de Moura EG 2004 Absence of anorectic effect to acute peripheral leptin treatment in adult rats whose mothers were malnourished during lactation. Horm Metab Res 36:625-629 
16. Coupé B, Amarger V, Grit I, Benani A, Parnet P 2010 Nutritional programming affects hypothalamic organization and early response to leptin. Endocrinology 151:702-713

17. Bouret SG, Draper SJ, Simerly RB 2004 Trophic action of leptin on hypothalamic neurons that regulate feeding. Science 304:108-110

18. Steppan CM, Swick AG 1999 A role for leptin in brain development. Biochem Biophys Res Commun 256:600-602

19. Fraga-Marques MC, Moura EG, Claudio-Neto S, Trevenzoli IH, Toste FP, Passos M, Lisboa PC, Manhaes AC 2009 Neonatal hyperleptinaemia programmes anxietylike and novelty seeking behaviours but not memory/learning in adult rats. Horm Behav 55:272-279

20. Roghair RD, Aldape G 2007 Naturally occurring perinatal growth restriction in mice programs cardiovascular and endocrine function in a sex-and strain-dependent manner. Pediatr Res 62:399-404

21. Magnotta VA, Harris G, Andreasen NC, O'Leary DS, Yuh WT, Heckel D 2002 Structural MR image processing using the BRAINS2 toolbox. Comput Med Imaging Graph 26:251-264

22. Siegmund A, Wotjak CT 2007 A mouse model of posttraumatic stress disorder that distinguishes between conditioned and sensitised fear. J Psychiatr Res 41:848-860

23. Komori T, Morikawa Y, Nanjo K, Senba E 2006 Induction of brain-derived neurotrophic factor by leptin in the ventromedial hypothalamus. Neuroscience 139:1107-1115

24. Conrad AL, Richman L, Lindgren S, Nopoulos P 2010 Biological and environmental predictors of behavioral sequelae in children born preterm. Pediatrics 125:e83-e89

25. Hack M, Youngstrom ER, Cartar L, Schluchter M, Gerry Taylor H, Flannery D, Klein N, Borawski E 2004 Behavioral outcomes and evidence of psychopathology among very low birth weight infants at age 20 years. Pediatrics 114:932-940

26. Spring S, Lerch JP, Henkelman RM 2007 Sexual dimorphism revealed in the structure of the mouse brain using three-dimensional magnetic resonance imaging. Neuroimage 35:1424-1433

27. Vasileiadis GT, Thompson RT, Han VK, Gelman N 2009 Females follow a more "compact" early human brain development model than males. A case-control study of preterm neonates. Pediatr Res 66:551-555

28. Vickers MH, Gluckman PD, Coveny AH, Hofman PL, Cutfield WS, Gertler A, Breier BH, Harris M 2008 The effect of neonatal leptin treatment on postnatal weight gain in male rats is dependent on maternal nutritional status during pregnancy. Endocrinology 149:1906-1913

29. Vickers MH, Gluckman PD, Coveny AH, Hofman PL, Cutfield WS, Gertler A, Breier BH, Harris M 2005 Neonatal leptin treatment reverses developmental programming. Endocrinology 146:4211-4216
30. Toste FP, de Moura EG, Lisboa PC, Fagundes AT, de Oliveira E, Passos MC 2006 Neonatal leptin treatment programmes leptin hypothalamic resistance and intermediary metabolic parameters in adult rats. Br J Nutr 95:830-837

31. Fraga-Marques MC, Moura EG, Silva JO, Claudio-Neto S, Pereira-Toste F, Passos MC, Lisboa PC, Manhães AC 2010 Effects of maternal hyperleptinaemia during lactation on short-term memory/learning, anxiety-like and novelty-seeking behavioral traits of adult male rats. Behav Brain Res 206:147-150

32. Schendel D, Bhasin TK 2008 Birth weight and gestational age characteristics of children with autism, including a comparison with other developmental disabilities. Pediatrics 121:1155-1164

33. Yang RJ, Mozhui K, Karlsson RM, Cameron HA, Williams RW, Holmes A 2008 Variation in mouse basolateral amygdala volume is associated with differences in stress reactivity and fear learning. Neuropsychopharmacology 33:2595-2604

34. Groen W, Teluij M, Buitelaar J, Tendolkar I 2010 Amygdala and hippocampus enlargement during adolescence in autism. J Am Acad Child Adolesc Psychiatry 49:552-560

35. Schumann CM, Barnes CC, Lord C, Courchesne E 2009 Amygdala enlargement in toddlers with autism related to severity of social and communication impairments. Biol Psychiatry 66:942-949

36. Roozendaal B, McReynolds JR, Van der Zee EA, Lee S, McGaugh JL, McIntyre CK 2009 Glucocorticoid effects on memory consolidation depend on functional interactions between the medial prefrontal cortex and basolateral amygdala. J Neurosci 29:14299-14308

37. Kibler JL, Joshi K, Ma M 2009 Hypertension in relation to posttraumatic stress disorder and depression in the US National Comorbidity Survey. Behav Med 34:125-132

38. Isaacs EB, Fischl BR, Quinn BT, Chong WK, Gadian DG, Lucas A 2010 Impact of breast milk on intelligence quotient, brain size, and white matter development. Pediatr Res 67:357-362

39. Attig L, Djiane J, Gertler A, Rampin O, Larcher T, Boukthir S, Anton PM, Madec JY, Gourdou I, Abdennebi-Najar L 2008 Study of hypothalamic leptin receptor expression in low-birth-weight piglets and effects of leptin supplementation on neonatal growth and development. Am J Physiol Endocrinol Metab 295:E1117E1125

40. Matochik JA, London ED, Yildiz BO, Ozata M, Caglayan S, DePaoli AM, Wong ML, Licinio J 2005 Effect of leptin replacement on brain structure in genetically leptin-deficient adults. J Clin Endocrinol Metab 90:2851-2854 